\title{
PENGEMBANGAN TARI SALONRENG DALAM KEHIDUPAN MASYARAKAT GOWA
}

\author{
Johar Linda \\ Pendidikan Sendratasik, Fakultas Seni dan Desain UNM \\ joharlinda@yahoo.co.id
}

\begin{abstract}
ABSTRAK
Penelitian yang berjudul Pengembangan Tari Salonreng dalam Kehidupan Masyarakat Gowa merupakan usaha untuk menyusuri keberadaan tari Salonreng baik sebagai tari ritual, maupun sebagai tari tontonan. Tari Salonreng sebagai tari ritual, mengandung nilai-nilai estetika, dan nilai-nilai filosofi, yang dapat dijadikan sebagai dasar pijakan dalam kehidupan bermasyarakat. Sementara itu, tari Salonreng sebagai tontonan prosesnya dapat menunjukkan sebuah gejala pengembangan yang bersifat ganda, yaitu; evolutif dan revolutif.Metode penelitian yang digunakan dalam tulisan ini adalah menggunakan metode penelitian kualitatif dengan pendekatan yang berpayung pada etnokoreologi. Pendekatan dengan menggunakan multidisiplin, diharapkan dapat mengungkap lebih dalam tentang pengembangan tari Salonreng dalam kehidupan masyarakat Gowa. Pengembangan gerak tari Salonreng, dari ritual menjadi tontonan disebabkan karena adanya pemanfaatan aset oleh pihak pariwisata. Tari Salonreng dalam ritual, sekarang ini ditarikan oleh seorang perempuan dewasa, gerak, musik iringan, menggunakan selendang panjang, kostum yang sederhana, dan pola lantai melingkar. Pertunjukan tari Salonreng sebagai tontonan, ditarikan oleh empat orang atau lebih (kelompok) gadis remaja. Penari kadang-kadang memakai selendang, kadang-kadang tidak menggunakan selendang, gerak dan musik iringan yang lebih variatif, kostum yang dikenakan lebih lengkap dengan aksesoris, dan pola lantai yang lebih beragam.
\end{abstract}

Kata kunci: tari, Salonreng, pengembangan, ritual, tontonan

\section{PENDAHULUAN}

Tari Salonreng adalah salah satu tari tradisonal di Kabupaten Gowa. Riwayat tari Salonreng hanya diketahui lewat cerita leluhur yang bersifat mitos ${ }^{1}$. Menurut mitos, kata Salonreng berasal dari kata $s a$ berarti pelaku gerak (orang yang bergerak) dan lonre(ma'lonre-lonre) yang artinya berkelompok. Maka Salonreng berarti tari yang dilakukan secara berkelompok. (Daeng Manda, wawancara 21 September 2015). Sementara itu, pengertian Salonreng yang lain dinyatakan oleh Halilintar bahwa kata Salonreng berarti selendang. (1995: 206)

Pada masa kejayaan Kerajaan Gowa, tari Salonreng dan tari Pakarena terjaga dan dilestarikan di dalam istana. Keduanya dipertunjukkan dalam kegiatan upacara kerajaan.

${ }^{1}$ Dalam peristilahan antropologi ini berarti bahwa mitos merupakan cerita-cerita suci yang harus dirumuskan sesuai fungsinya. Mitos merupakan kisah yang diceritakan untuk menetapkan kepercayaan tertentu, berperan sebagai peristiwa pemula dalam suatu upacara atau ritus, atau sebagai model tetap dari perilaku moral maupun religius. (Lihat Dhavamony, 1995: 150) 
Tari Salonreng ditarikan oleh empat orang wanita tua. Hal tersebut berhubungan dengan kepercayaan masyarakat Gowa pada konsep appa sulapa (persegi empat). Appa sulapa dihubungkan dengan empat unsur bumi, yaitu butta (tanah), je'ne (air), pepe (api) dan anging (angin). (Daeng Manda, wawancara 21 September 2015). Sementara itu tari Pakarena ditarikan oleh gadis-gadis remaja, dalam jumlah genap dari kalangan keluarga kerajaan. Kedua tari tersebut berkembang sejalan dengan perkembangan dan kejayaan kerajaan Gowa. Setelah kerajaan Gowa runtuh, maka lambat laun eksistensi tari Pakarena dan tari Salonreng juga ikut runtuh, dan mendapatkan patronese (perlindungan) baru dari kalangan non-istana, yakni orang desa yang kaya.

Tari Salonreng pada ritual diyakini mengandung makna appakase're sumanga' (menyatukan jiwa/roh) dengan semua yang diupacarakan. Syarat utama untuk menjadi Pasalonreng (penari Salonreng) adalah telah bersih secara spiritual (menopouse), dan dianggap berpengalaman dalam kehidupan ${ }^{2}$.

Selain di Kabupaten Gowa, eksistensi tari Salonreng dapat ditemui di beberapa daerah yang tergolong sebagai masyarakat etnis Makassar, yaitu; Kabupaten Takalar, Kabupaten Je'neponto, Kabupaten Bantaeng, Kabupaten Bulukumba, dan Kabupaten Kepulauan Selayar. Masing-masing daerah mengembangkan dan melestarikan tari Salonreng dengan mengisi upacara inisiasi (upacara adat sunatan, dan pernikahan) serta hiburan pada acara-acara pemerintahan.

Tari Salonreng di Kabupaten Gowa berbeda dengan tari Salonreng di daerah lain. Perbedaan tersebut adalah tari Salonreng di Kabupaten Gowa dilakukan oleh satu orang wanita dewasa, sedangkan di daerah lain biasanya dilakukan oleh gadis remaja dengan jumlah genap (dua, empat atau enam orang). Tari Salonreng di Kabupaten Gowa dilakukan untuk ritual persembahan kepada Batara (yang maha kuasa) juga dilakukan sebagai tari tontonan, sedangkan di daerah lain sebagai hiburan. Tari Salonreng diyakini sebagai pengantar roh hewan persembahan kepada Batara. (Daeng Manda, wawancara 21 September 2015).

Tari Salonreng yang dilaksanakan di Kabupaten Gowa, bukan saja dilaksanakan pada ritual attammu taung, accera' ase dan upacara adat sunatan akan tetapi dilaksanakan pula pada upacara adat perkawinan pada prosesi akkorontigi ${ }^{3}$. Pelaksanaan Salonreng pada prosesi akkorontigi dalam upacara adat perkawinan hanya terbatas pada keturunan bangsawan. Pelaksanaan kegiatan upacara akkorontigi dengan menyajikan Salonreng dipercayai memberikan dampak besar dalam menata kehidupan masyarakat, yaitu dapat memberikan keselamatan, kesejahteraan dan kebahagiaan dalam rumah tangga. (Nurdin Amir, wawancara 15 Desember 2014)

Tari Salonreng di Kabupaten Gowa pernah vakum karena adanya gerakan Darul Islam (DI), Tentara Islam Indonesia (TII) dan Pemberontakan Perjuangan Rakyat Semesta (Permesta) tahun 1957 serta pergolakan yang berbau Islam pada tahun 1960-an, yang dikenal dengan nama Operasi Taubat (tobak), yang dilakukan oleh Partai Islam Reformis Muhammadiyah.Hal tersebut mengakibatkan intimidasi kepada orang-orang yang tidak mendukung Islam ortodoks, termasuk pelaku praktek-praktek ritual lokal

${ }^{2}$ Selain pandai menari (bergerak) seorang Pasalonreng harus bisa berkomunikasi dengan alam gaib, dan memiliki beberapa ilmu yang tidak dimiliki oleh perempuan umumnya, misalnya ilmu pengobatan yang menggunakan mantera-mantera.(Hj. Nuraeni Daeng Kebo, wawancara 05-09-2013).

${ }^{3}$ Akkorontigi (malam pacar) adalah upacara membubuhi ramuan daun pacar pada kuku dan telapak tangan calon pengantin, baik laki-laki maupun perempuan, merupakan simbol kebersihan dan kesucian. Upacara tersebut dilakukan sehari sebelum akad nikah dilaksanakan yang berarti malam mensucikan diri.(Solihing, 2004: 51-53) 
misalnya pemusik, penari dan dukun (sanro) (Sutton, 2013: 32). Gerakan tersebut melarang adanya kegiatan-kegiatan ritual, karena menganggap kegiatan tersebut menentang dan menyalahi ajaran Islam, namun peralatan musiknya dapat diselamatkan oleh pendukung tari tersebut, dan pembinaannya diambil alih oleh anrong guru. (Abd. Muin, wawancara 10 Januari 2015)

Perkembangan dan pelestarian tari Salonreng mulai dilaksanakan oleh anrong guru. Eksistensinya dapat dilihat di pedesaan-pedesaan dan daerah-daerah pinggiran, karena masih dilakukan secara sembunyi-sembunyi. Setelah tahun 1970-an, barulah pemerintah memberi kebebasan kepada masyarakat untuk mengembangkan kesenian dan tarian sebagai warisan leluhur. Sejak saat itu, seniman-seniman Makassar, di antaranya, Andi Nurhani Sapada, Munasiah Nadjamuddin, Manda, Siradjuddin Bantang mulai menggalakkan kembali tari-tari tradisional yang ada di Kabupaten Gowa dan kota Makassar, dengan mengadakan kegiatan pelatihan tari dan musik. (Munasiah, wawancara 21 September 2015).

Tari Salonreng yang dilakukan pada ritual attammu taung dan upacara sunatan di Kecamatan Somba Opu Kabupaten Gowa, merupakan syarat utama ritual yang dilaksanakan untuk appalappasa tinja' (melepas nazar). Prosesi tari Salonreng dilakukan setelah kerbau disembelih sebagai hewan persembahan yangberfungsi sebagai pengantar roh hewan persembahan kepada sang pencipta (Tuhan Yang Maha Esa). Pasalonreng melakukan gerakan tari Salonreng sambil mengelilingi kerbau tersebut. Gerakannya sangat sederhana, terdiri dari satu ragam, yaitu ragam Salonreng, dengan tiga gerak yaitu appakaramula gio' (memulai gerakan), akkalimbu cinde (menutupi badan dengan selendang), attoeng cinde (mengayun selendang).

Perkembangan tari Salonreng sekarang ini dipengaruhi oleh pariwisata, berdampak pada hal-hal yang bersifat positif. Nilai positif yang bisa dipetik adalah, para generasi muda dapat lebih mengenal dan mengetahui tentang tari Salonreng yang ada di Kabupaten Gowa. Tari Salonreng selain dilaksanakan pada upacara ritual, juga dilaksanakan pada acara-acara tertentu sebagai tontonan. Anrong Guru Salonreng melestarikan tari Salonreng dengan cara melaksanakan atau menampilkan tari Salonreng dalam upacara ritual accera' ase, attammu taung, akkorontigi, dan upacara sunatan.

\section{METODE PENELITIAN}

Metode penelitian yang digunakan dalam tulisan ini adalah menggunakan metode penelitian bersifat kualitatif dengan pendekatan yang berpayung pada etnokoreologi. Pendekatan dengan menggunakan multidisiplin, diharapkan dapat mengungkap lebih dalam tentang pengembangan tari Salonrengdalam kehidupan masyarakat Gowa.

Metode penelitian yang digunakan adalah etnografi tari. Tulisan Joan D. Frosh dengan judul "Dance Ethnography: Tracing the Weave of Dance in the Fabric of Culture", dalam buku Researching Dance Evolving Modes of Inquiry editor Sondra Horton Fraleigh dan Penelope Hanstein, dijadikan sebagai sumber acuan dalam penelitian ini.

Metode pengumpulan data yang digunakan Joan D. Frosh adalah, observasi, studi pustaka, dan wawancara serta metode analisis, kemudian memberikan interpretasi untuk mendapatkan kesimpulan. Model penelitian yang digunakan oleh Joan D. Frosh untuk memperoleh data ada 10 langkah, yaitu; 1)Menentukanpendekatan studitaridalam budayadengan istilah sendiri, menelitiapa dan bagaimanatariandalam kaitannya dengankontekspadasebuah wilayah. 2)Mengujitradisipertunjukan sebagaiekspresi. 3)Meneliti bagaimanakonstruksipertunjukan danmemediasigagasansosialgender, status,spiritualitas, danlembaga. 4)Mengeksplorasiinteraksietikadan estetikadalam 
pertunjukan danmasyarakat. 5)Menguji hubungantari,dengan carapengorganisasianpengalaman hidup, misalnya, ritual, pernikahan, pendidikan, rekreasi, ekspresiestetika, penyembuhan, Ritus peralihan, kerja. 6)Mengujidinamikataridalamkontinuitasdan perubahan. 7)Mengujiperanandaripelakudalam masyarakatdan untuk mengeksplorasiproses kreatifpertunjukantari. 8)Mengetahuiperanpenelitidalam membentukpenelitian, dan untuk mengeksplorasihubunganantaraperubahanpemaindan penelitididuniapostkolonial. 9) Menempuh jalan untuk membangun sebuah etos gerakan melalui berbagai modalitas, yaitu observasi, perwujudan, empati kinestetik, menulis, diskusi, kolaborasi, dan pertunjukan. 10)Menentukan apadan bagaimanabelajar dan berpartisipasi dalampertunjukan. (1998: 249)

Penerapan metode kerja lapangan tersebut, diharapkan dapat mengungkapkan tentang pengembangan tari Salonrengdalam kehidupan masyarakat Gowa. Peneliti sebagai orang Gowa, yang bertindak sebagai partisipant observer, hal ini diperlukan untuk melihat secara detail bagaimana bentuk tari Salonreng, bagaimana penjiwaan dan interpretasi masyarakat tentang tari Salonreng. Selain itu, peneliti juga harus menjaga jarak agar tidak terlalu dipengaruhi oleh lingkungan sekitar.

\section{HASIL DAN PEMBAHASAN}

Pengembangan gerak tari Salonreng, dari tari ritual menjadi tari tontonan disebabkan karena adanya pemanfaatan aset oleh pihak pariwisata. Apabila fungsi tari berubah, maka bentuk tarinya ikut pula berubah, baik dari gerak, pola lantai, jumlah penari, kostum, dan penggunaan properti. Tari Salonreng dalam ritual, sekarang ini ditarikan oleh seorang perempuan dewasa, gerak, musik iringan, menggunakan selendang panjang, kostum yang sederhana, dan pola lantai melingkar. Pertunjukan tari Salonreng sebagai tontonan, ditarikan oleh empat orang atau lebih (kelompok) gadis remaja. Penari kadang-kadang memakai selendang, kadang-kadang tidak menggunakan selendang, gerak dan musik iringan yang lebih variatif, kostum yang dikenakan lebih lengkap dengan aksesoris, dan pola lantai yang lebih beragam. (Munasiah, wawancara 21 September 2015)

Sekarang ini tari Salonreng, dilakukan sebagai tari ritual, dan sebagai tari profan (pertunjukan). Sejalan dengan perkembangan zaman, tari Salonreng telah berubah fungsi sebagai seni pertunjukan, dan bentuk tarinyapun ikut berubah. Tari Salonreng sebagai ritual untuk kebutuhan pariwisata lebih dikenal dengan pseudoritual (ritual semu). Tari Salonreng yang dilaksanakan pada acara pembukaan Pentas Seni Budaya Selat Makassar adalah Pseudoritual, yang dilaksanakan di Benteng Fort Rotterdam pada tanggal 5 Desember 2012. Pada pertunjukan tersebut, tari Salonreng berkolaborasi dengan pertunjukan Bissu. Tari Salonreng sebagai upacara ritual appanai' dengan maksud untuk memohon perlindungan dan memohon restu kepada Tuhan Yang Maha Esa, agar acara tersebut dapat berlangsung dengan lancar dan sukses.

Tari Salonreng ditampilkan pula sebagai Pseudoritual pada acara pembukaan Festival Musik Nusantara yang diselenggarakan oleh etnomusikologi ISI Yogyakarta tanggal 12 Mei 2014. Pementasan tersebut ditarikan oleh empat orang perempuan, dengan gerak dan musik iringan serta pola lantai yang lebih variatif, menggunakan selendang warna putih, kostum sederhana (baju kaos putih dengan sarung hitam).

Tari Salonreng untuk pariwisata disebut juga sebagai seni pseudoritual (ritual semu). Ditampilkan secara ritual, akan tetapi bukan ritual yang sebenarnya, melainkan sebagai tiruan ritual. Dilihat dari gerak, musik iringan, pola lantai, kostum, dan properti, sedangkan sesaji, dipersiapkan hanya sebahagian kecil atau sebagai simbol. Tari Salonreng untuk pariwisata sesuai dengan ciri-ciri pertunjukan pariwisata konsep R.M. 
Soedarono, yaitu; 1) tiruan dari aslinya, 2) singkat dan padat atau bentuk mini dari aslinya, 3) penuh variasi, 4) meninggalkan nilai-nilai sakral, magis, dan simbolisnya, dan 5) murah harganya. (1999: 8)

Tari Salonreng masih dilakukan untuk kepentingan ritual dalam kehidupan masyarakat Gowa. Masyarakat Gowa memelihara dan melestarikan tari Salonreng dalam upacara ritual maupun tontonan. Tari Salonreng dipentaskan dalam ritual attammu taung, hal ini hanya dilaksanakan di Kabupaten Gowa. Dalam pelaksanaan ritual mempunyai ciri-ciri dan syarat-syarat serta struktur pelaksanaan yang berbeda. Tari Salonreng yang dilaksanakan sebagai tontonan dipentaskan pada acara Hari Tari Sedunia (HTD) di pelataran parkir kampus Universitas Negeri Makassar (UNM) di Makassar tanggal 29 April 2011. Pada acara tersebut tari Salonreng ditarikan oleh seorang perempuan, dengan gerak, musik, pola lantai, tata rias dan busana yang lengkap, menggunakan properti selendang warna putih.

\section{KESIMPULAN DAN SARAN}

Tari Salonreng adalah salah satu tari tradisonal di Kabupaten Gowa. Riwayat tari Salonreng hanya diketahui lewat cerita leluhur yang bersifat mitos. Menurut mitos, kata Salonreng berasal dari kata sa berarti pelaku gerak (orang yang bergerak) dan lonre(ma'lonre-lonre) yang artinya berkelompok. Maka Salonreng berarti tari yang dilakukan secara berkelompok. (Daeng Manda, wawancara 21 September 2015). Sementara itu, pengertian Salonreng yang lain dinyatakan oleh Halilintar bahwa kata Salonreng berarti selendang. (1995: 206)

Tari Salonreng yang dilaksanakan di Kabupaten Gowa, bukan saja dilaksanakan pada ritual attammu taung, accera' ase dan upacara adat sunatan akan tetapi dilaksanakan pula pada upacara adat perkawinan pada prosesi akkorontigi. Pelaksanaan Salonreng pada prosesi akkorontigi dalam upacara adat perkawinan hanya terbatas pada keturunan bangsawan, yang dipercayai memberikan dampak besar dalam menata kehidupan masyarakat, yaitu dapat memberikan keselamatan, kesejahteraan dan kebahagiaan dalam rumah tangga.

Tari Salonreng untuk pariwisata sesuai dengan ciri-ciri pertunjukan pariwisata konsep R.M. Soedarono, yaitu; 1) tiruan dari aslinya, 2) singkat dan padat atau bentuk mini dari aslinya, 3) penuh variasi, 4) meninggalkan nilai-nilai sakral, magis, dan simbolisnya, dan 5) murah harganya. (1999: 8)

\section{DAFTAR PUSTAKA}

Abdullah, Hamid. 1985. Manusia Bugis Makassar, Jakarta: Inti Idayu Press.

Latief, Halilintar dan Niniek Sumiani HL. 1994. Pakarena, Sebuah Bentuk Tari Tradisi Makassar, Departemen Pendidikan dan Kebudayaan.

Linda, Johar. 2013. Tari Salonreng Dalam Upacara Ritual Accera' Ase, Yogyakarta: IKKJ Publiser

Mattulada. 1990. Menyusuri Jejak Kehadiran Makassar Dalam Sejarah (1510 - 1700), Ujung Pandang: Lembaga Penerbitan Universitas Hasanuddin.

Monoharto, Gunawan, et al. 2004. Seni Tradisional Sulawesi Selatan, Makassar: Lamacca Press.

Soedarsono, 1999. Seni Pertunjukan Indonesia dan Pariwisata, Bandung; MSPI (Masyarakat Seni Pertunjukan Indonesia), cet. 1. , 2001. Metodologi Penelitian Seni Pertunjukan dan Seni Rupa,Bandung: MSPI (Masyarakat Seni Pertunjukan Indonesia), cet. ke-2. 
2002. Seni Pertunjukan Indonesia di Era Globalisasi,Yogyakarta: Gadjah Mada University Press.

, 2003. Seni Pertunjukan Dari Perspektif Politik, Sosial, dan Ekonomi, Yogyakarta: Gadjah Mada University Press 